ARTICLE

\title{
Divergent functionalization of aldehydes photocatalyzed by neutral eosin $Y$ with sulfone reagents
}

\author{
Jianming Yan (1) 1,2,5, Haidi Tang 1,3,5, Eugene Jun Rong Kuek ${ }^{1}$, Xiangcheng Shi ${ }^{1}$, Chenguang Liu', \\ Muliang Zhang (1) ${ }^{1 凶}$, Jared L. Piper ${ }^{4}$, Shengquan Duan (i) ${ }^{4 凶} \&$ Jie Wu $\mathbb{B}^{1,3 凶}$
}

While aldehydes represent a classic class of electrophilic synthons, the corresponding acyl radicals are inherently nucleophilic, which exhibits umpolung reactivity. Generation of acyl radicals typically requires noble metal catalysts or excess oxidants to be added. Herein, we report a convenient and green approach to access acyl radicals, capitalizing on neutral eosin $\mathrm{Y}$-enabled hydrogen atom transfer (HAT) photocatalysis with aldehydes. The generated acyl radicals underwent SOMOphilic substitutions with various functionalized sulfones $\left(X-\mathrm{SO}_{2} \mathrm{R}^{\prime}\right)$ to deliver value-added acyl products. The merger of eosin $\mathrm{Y}$ photocatalysis and sulfone-based SOMOphiles provides a versatile platform for a wide array of aldehydic $\mathrm{C}-\mathrm{H}$ functionalizations, including fluoromethylthiolation, arylthiolation, alkynylation, alkenylation and azidation. The present protocol features green characteristics, such as being free of metals, harmful oxidants and additives; step-economic; redox-neutral; and amenable to scale-up assisted by continuous-flow technology.

\footnotetext{
${ }^{1}$ Department of Chemistry, National University of Singapore, 3 Science Drive 3, Singapore 117543, Republic of Singapore. ${ }^{2}$ Department of Medicinal Chemistry, College of Pharmacy, Chongqing Medical University, Chongqing 400016, China. ${ }^{3}$ National University of Singapore (Suzhou) Research Institute, 377 Lin Quan Street, Suzhou Industrial Park, Suzhou, Jiangsu 215123, China. ${ }^{4}$ Pfizer Worldwide Research and Development, Eastern Point Rd, Groton, CT

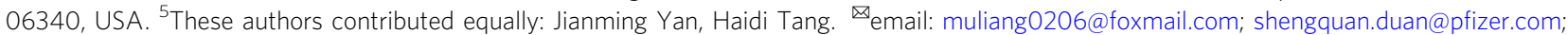
chmjie@nus.edu.sg
} 
A cyl radicals are versatile synthetic intermediates in $\mathrm{C}-\mathrm{C}$ bond-forming reactions, such as Giese addition ${ }^{1,2}$ and Minisci acylation $^{3}$, as well as transition metal-mediated cross-coupling reactions ${ }^{4-6}$. The exploration of acyl radical chemistry greatly expanded the scope of accessible carbonylcontaining functional molecules ${ }^{7}$. However, conventional approaches to accessing acyl radicals normally require harsh conditions such as high temperature, ultraviolet irradiation, or the use of hazardous reagents. Emerging and rapidly expanding photocatalysis has offered enormous opportunities to access acyl radicals in a green and sustainable fashion from a variety of precursors, including aldehydes, carboxylic acids, acid derivatives, and acyl silanes ${ }^{8-13}$. Among them, the use of aldehydes for acyl radical generation represents the most straightforward and atomand step-economical pathway.

By taking advantage of aldehyde feedstocks as acyl radical precursors $^{14-16}$, a plethora of acyl-C bond-forming reactions have been developed. This bond formation is normally realized by acyl radical addition to unsaturated alkenes or (hetero)aromatics, leading to acyl-C $\left(s p^{3}\right)$ or acyl-C $\left(s p^{2}\right)$ bond formation. In stark contrast, the construction of acyl-X $(\mathrm{X}=\mathrm{S}, \mathrm{N}, \mathrm{D})$ and acyl- $\mathrm{C}(s p)$ bonds from aldehydes is largely underexplored (Fig. 1a). Excess oxidants $^{17,18}$, additives ${ }^{19,20}$, or noble metal catalysts ${ }^{21-24}$ are usually required to achieve such transformations.

Direct photocatalyzed hydrogen atom transfer (HAT) has enabled a remarkable breakthrough in $\mathrm{C}-\mathrm{H}$ functionalizations ${ }^{25,26}$.
Capitalizing on HAT activity of C-O biradical of excited ketones or quinones, a series of HAT photocatalysts were developed ${ }^{27-31}$. Although anionic eosin $\mathrm{Y}$ was commonly used as a photoredox catalys $^{32-34}$, a previous study by our group established neutral eosin $\mathrm{Y}$ as an excellent direct HAT photocatalyst that can activate a wide range of $\mathrm{C}-\mathrm{H}$ bonds to access the corresponding carbon radicals under simple and mild conditions ${ }^{35}$. Eosin $\mathrm{Y}$ was capable of providing access to acyl radicals from aldehyde feedstocks, which have been employed to react with alkenes and alkynes for asymmetric 1,4 -addition ${ }^{36}$ and a radical Smiles rearrangement ${ }^{37}$, respectively. With the cumulative insights gained from the eosin Y-HAT photocatalytic system ${ }^{38}$, we envisioned that its merger with sulfone SOMOphiles ${ }^{39,40}$ can provide a general platform for aldehydic $\mathrm{C}-\mathrm{H}$ functionalization to access various types of functional acyl compounds. Acyl radicals generated by photoinduced HAT undergo nucleophilic substitution with $\mathrm{X}-\mathrm{SO}_{2} \mathrm{R}^{\prime}$, which will benefit from polarity matching ${ }^{41-43}$, delivering diverse functionalized acyl compounds accompanied by electrophilic sulfonyl radical species. The sulfonyl radical then participates in a reversed HAT (RHAT) process with eosin $\mathrm{Y}-\mathrm{H}$ to complete the catalytic cycle.

In this work, by using different SOMOphilic sulfone reagents as acyl radical traps in HAT photocatalysis, we achieve aldehydic $\mathrm{C}-\mathrm{H}$ fluoromethylthiolation, arylthiolation, alkynylation, alkenylation, and azidation (Fig. 1b). Notably, arylsulfinic acid is utilized as an odorless thiolation reagent for thioester generation. Compared to existing protocols for aldehydic $\mathrm{C}-\mathrm{H}$ functionalizations, eosin

a Selected existing aldehydic $\mathrm{C}-\mathrm{H}$ functionalizations

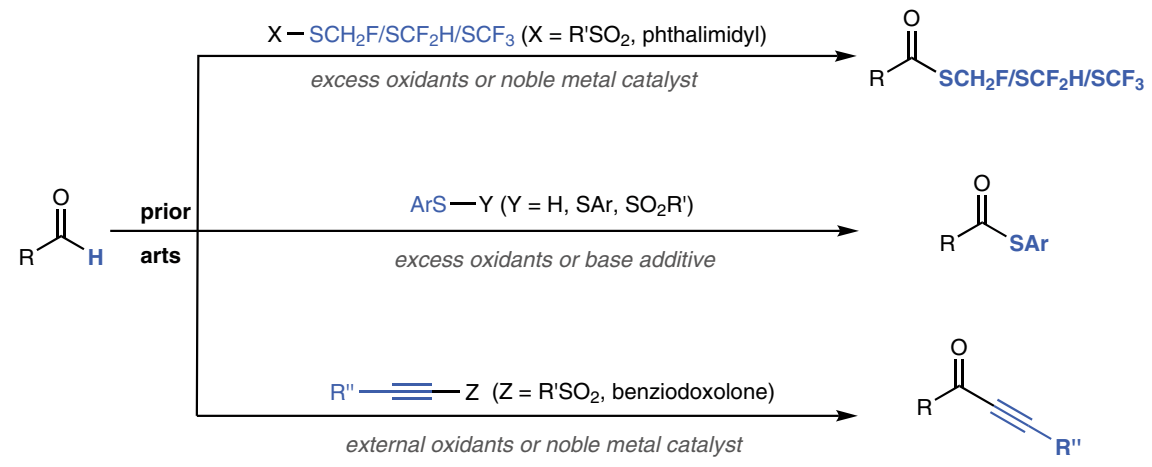

b Diverse aldehydic $\mathrm{C}-\mathrm{H}$ functionalizations enabled by eosin $\mathrm{Y}-\mathrm{HAT}$ photocatalysis

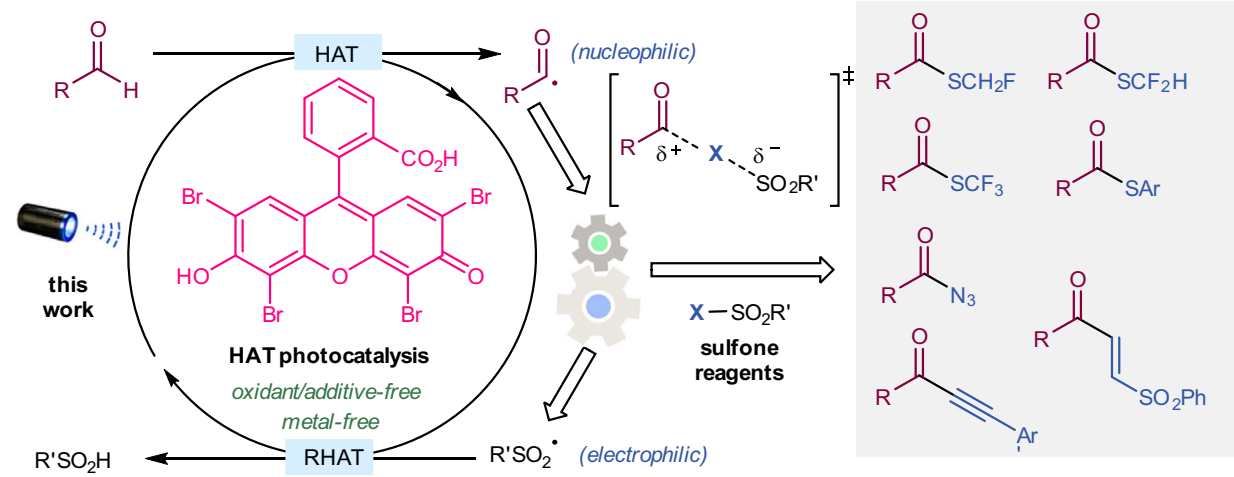

$\begin{array}{llllll}\begin{array}{l}\text { sulfone } \\ \text { reagents }\end{array} & \mathrm{PhSO}_{2} \mathrm{SCH}_{2} \mathrm{~F} & \mathrm{PhSO}_{2} \mathrm{SCF}_{2} \mathrm{H} & \mathrm{PhSO}_{2} \mathrm{SCF}_{3} & \mathrm{ArSO}_{2} \mathrm{H} \text { (odorless thiolation) } \\ & \mathrm{CH}_{3} \mathrm{SO}_{2}=- & \begin{array}{lll}\mathrm{Ar} & \mathrm{CF}_{3} \mathrm{SO}_{2} \mathrm{~N}_{3} & \mathrm{PhO}_{2} \mathrm{~S}\end{array} \mathrm{SO}_{2} \mathrm{Ph}\end{array}$

Fig. 1 Diverse aldehydic C-H functionalizations. a Selected existing aldehydic $\mathrm{C}-\mathrm{H}$ functionalizations. b This work: diverse aldehydic $\mathrm{C}-\mathrm{H}$ functionalizations by HAT photocatalysis using sulfone regents. 
Y-HAT photocatalysis features operationally simple, inexpensive, and metal-, oxidant-, and additive-free green attributes.

\section{Results}

Development of aldehydic $\mathrm{C}-\mathrm{H}$ fluoromethylthiolation. The monofluoromethylthio moiety $\left(\mathrm{SCH}_{2} \mathrm{~F}\right)$ widely exists in a variety of biologically active compounds (Supplementary Fig. 1) ${ }^{44,45}$. Previous reports to achieve aldehydic $\mathrm{C}-\mathrm{H}$ monofluoromethylthiolation relied on the use of stoichiometric oxidants such as 2,2'-azodi(2methylbutyronitrile) $(\mathrm{AMBN})^{46}$ or $\mathrm{PhI}\left(\mathrm{O}_{2} \mathrm{CCF}_{3}\right)_{2} / \mathrm{NaN}_{3}{ }^{17}$. We envisioned that eosin Y-based HAT photocatalysis may enable this transformation in a redox-neutral fashion. After extensive condition optimization using benzaldehyde 1a and $S$-(fluoromethyl) benzenesulfonothioate $\left(\mathrm{PhSO}_{2}-\mathrm{SCH}_{2} \mathrm{~F}\right)$ 2a as the model substrates (Supplementary Table 1), we found that neutral eosin Y (4 mol\%) in tert-butanol $(t \mathrm{BuOH})$ under blue light $(18 \mathrm{~W}, 470 \mathrm{~nm}$ LED) irradiation at ambient temperature afforded desired product $\mathbf{3 a}$ in optimal yield (88\%). Notably, no product was generated using anionic eosin $\mathrm{Y}$ as the photocatalyst, while other photocatalytic systems for HAT, 22,24,27,47 gave inferior product yields (Supplementary Table 4), highlighting the effectiveness of eosin Y catalysis. Light irradiation was essential, as no product was detected when the reaction was performed in darkness.

With the optimized conditions, the scope of aldehydes amenable to monofluoromethylthiolation was investigated (Fig. 2). Electron-rich (3b-f) and electron-deficient $(\mathbf{3 g}-\mathbf{k})$ arene derivatives possessing ortho-, meta-, or para-substituents all provided the corresponding monofluoromethyl thioester products in $55-78 \%$ yields. A wide range of functionalities, including ether (3b-e), phenol (3d), thioether (3f), halide (3h, 3i), and cyanide (3j), were well tolerated. Naphthalene- or heterocycle (such as benzodioxole and benzothiophene)-substituted aldehydes smoothly participated in the transformation to afford products 31-n in good yields (72-92\%). The scope with respect to aliphatic aldehydes was evaluated next. Both linear (3o-r) and branched (3s, 3t) alkyl aldehydes afforded the desired products in good yields (67-88\%). The incorporation of amide (3q), terminal alkene (3r) and piperidine (3t) substrates was compatible with our conditions. However, tertiary aldehydes such as pivalaldehyde failed to give the corresponding product (not shown), probably due to the facile decarbonylation of the unstable tert-alkyl acyl radical $^{48}$. Moreover, the protocol can be applied to late-stage functionalization of natural product derivatives. Useful yields (46-54\%) of monofluoromethylthiolation products were obtained with complex molecules derived from (-)-menthol (3u), $(+)$-fenchol (3v), and lithocholic acid (3w). Importantly, by simply changing fluoromethylthio-sulfone reagents $\mathbf{2 a}$ to $\mathbf{2 b}$ $\left(\mathrm{PhSO}_{2}-\mathrm{SCF}_{2} \mathrm{H}\right)$ and $2 \mathrm{c}\left(\mathrm{PhSO}_{2}-\mathrm{SCF}_{3}\right)$, this protocol could be successfully extended to aldehydic $\mathrm{C}-\mathrm{H}$ difluoromethylthiolation $(3 \mathbf{x})$ and trifluoromethylthiolation $(\mathbf{3 y}, \mathbf{3 z})$, respectively, representing a general method to access diverse fluoromethylthioesters in a simple and green manner.

Development of aldehydic C-H thiolation using arylsulfinic acid as an odorless sulfur reagent. During the study of aldehydic $\mathrm{C}-\mathrm{H}$ fluoromethylthiolation, we found that the eosin Y-photocatalyzed reaction between 4-methoxybenzaldehyde $\mathbf{1 b}$ and $\mathbf{2 a}$ gave major product $\mathbf{3 b}$ accompanied by $S$-phenyl thioester $\mathbf{4 b}$ in $>20 \%$ yield (Fig. 3a). In light of our previous study on HAT photocatalysis ${ }^{34}$ and related reports on photocascade catalysis ${ }^{49-51}$, we speculated that $S$-phenyl thioester $\mathbf{4 b}$ might be derived from benzenesulfinic acid 5a generated in situ (Fig. 3b). The photo-generated acyl radical $\mathbf{A}$ underwent radical substitution with $\mathbf{2 a}$ to deliver monofluorothiolation product $\mathbf{3}$ and benzenesulfonyl radical B simultaneously. RHAT with eosin Y-H would convert benzenesulfonyl radical $\mathbf{B}$ to benzenesulfinic acid $\mathbf{5 a}$, which accumulated in the reaction mixture and served as the sulfur reagent for thiolation. This hypothesis was verified by treatment of $\mathbf{1 b}$ with $\mathbf{5 a}$ under eosin $\mathrm{Y}$ photocatalysis conditions, which delivered thioester $\mathbf{4 b}$ in $68 \%$ yield (Fig. $3 \mathrm{c}$ ).

Given the synthetic value of thioesters ${ }^{52}$ and the appealing property of arylsulfinic acid as an odorless and readily available sulfur reagent, we attempted to examine the arylthiolation scope of this operationally simple method (Fig. 4). A diverse set of aromatic aldehydes took part in this transformation to give moderate to good yields (46-71\%) of thioester products (4a-k), tolerating a variety of functional moieties such as amide (4d), ester (4e, 4j), halide $(\mathbf{4} \mathbf{h})$, trifluoromethyl (4i), and 2,2difluorobenzodioxole (4k) groups. Aromatic aldehydes with para-, meta-, or ortho-substituents smoothly participated in the transformation. Heteroaryl $(\mathbf{4 l}, \mathbf{4 m})$ and alkyl $(\mathbf{4 n}, \mathbf{4 o})$ aldehydes were also amenable to thiolation, but with lower yields (22-50\%), where a substantial amount of sulfonic acids was observed as the side-products. Furthermore, variation with respect to arylsulfinic acids was evaluated, illustrating that a broad scope of (hetero) arylsulfinic acids afforded the corresponding thioesters $(\mathbf{4} \mathbf{p}-\mathbf{u})$ in useful yields (40-61\%).

To gain a mechanistic understanding of the aldehydic $\mathrm{C}-\mathrm{H}$ arylthiolation, a range of control experiments were performed to elucidate the reaction intermediates. Various $S$-phenyl sources were examined (Fig. 5a). Both benzenesulfinic acid 5a and $S$ phenyl benzenesulfonothioate $9 a$ could afford thioester $\mathbf{4 b}$ in good yields, while other $S$-aryl sources such as benzenesulfonic acid $\mathbf{6}$, thiol 7 , disulfide $\mathbf{8}$, and disulfone $\mathbf{1 0}$ were not effective at all or delivered $\mathbf{4 b}$ in very low yields. These results indicated that arylthiosulfonate $\mathbf{9}$ may act as a key intermediate in the reaction. This was further supported by the fact that benzenesulfinic acid 5 a could be converted to $S$-phenyl benzenethiosulfonate $\mathbf{9 a}$ under eosin Y photocatalytic conditions, but 9a could not be generated in the absence of eosin Y (Fig. 5b). The reaction became sluggish with the addition of radical scavengers such as 2,2,6,6tetramethylpiperidin-1-yl)oxyl (TEMPO) and butylated hydroxytoluene (BHT), supporting a radical-based mechanism. When 1,1-diphenylethylene was added as an additive, adducts $\mathbf{1 1}$ and $\mathbf{1 2}$ were detected by electrospray ionization mass spectrometry (ESIMS), indicating the presence of arylsulfonyl radicals and acyl radicals, respectively (Fig. 5 c). Moreover, ${ }^{18} \mathrm{O}$ incorporation was not observed when ${ }^{18} \mathrm{O}$-labeled 4 -methylbenzenesulfinic acid ${ }^{18} \mathrm{O}-5 \mathbf{b}^{53}$ was employed, which suggested that the carbonyl oxygen in the thioester product was derived from the aldehyde (Fig. 5d).

In light of all the experimental data and related literature, a tentative mechanistic pathway for aldehydic $\mathrm{C}-\mathrm{H}$ arylthiolation is proposed (Fig. 5e). Photo-excited *eosin Y undergoes HAT with benzenesulfinic acid $\mathbf{5 a}$ to generate benzenesulfonyl radical $\mathbf{B}^{54}$, which dimerizes to give disulfone species $\mathbf{1 0} \mathbf{1 0}$ is reduced by benzenesulfinic acid 5a to give thiosulfonate $\mathbf{9 a}^{55,56}$. 9a then participates in radical substitution with acyl radical $\mathbf{A}$, which is formed via eosin Y-HAT photocatalysis with aldehyde $\mathbf{1}$. Arythioester product $\mathbf{4}$ is obtained together with arylsulfonyl radical $\mathbf{B}$, which closes the photocatalytic cycle and regenerates benzenesulfinic acid 5a (see Supplementary Fig. 12 for more discussion).

Development of Aldehydic C-H Alkynylation. To further demonstrate HAT photocatalysis by eosin $\mathrm{Y}$ with sulfone reagents as a versatile platform for aldehydic $\mathrm{C}-\mathrm{H}$ functionalizations, we found that methanesulfonyl alkyne 13aa was a suitable alkynylation reagent to deliver synthetically valuable ynone compounds (Fig. 6). A series of alkynyl sulfones bearing different $\mathrm{R}^{\prime}$ 


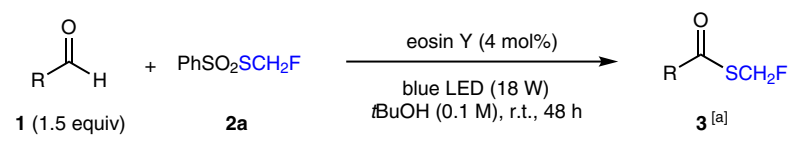<smiles>O=C(SCF)c1ccccc1</smiles>

3a, $88 \%$<smiles>CC(C)(C)Oc1ccc(C(=O)SCF)cc1</smiles>

$3 e, 78 \%$<smiles>O=C(SCF)c1ccc(Br)cc1</smiles>

$3 \mathbf{i}, 75 \%$<smiles>O=C([SeH]F)c1ccc2c(c1)OC(F)(F)O2</smiles>

$3 \mathrm{~m}, 92 \%$<smiles>O=C(CCCN1C(=O)c2ccccc2C1=O)[SeH]F</smiles>

3q, $88 \%$<smiles>COc1ccc(C(=O)OCCCCCCO)cc1</smiles>

3b, $75 \%$<smiles>CS(=O)(=O)c1ccc(C(=O)F)cc1</smiles>

3f, $76 \%$<smiles>N#Cc1ccc(C(=O)[Se]F)cc1</smiles>

3j, $65 \%$<smiles>O=C([SeH]F)c1cc2ccccc2s1</smiles>

3n, $80 \%$<smiles>C=CCCCCCCCCC(=O)[SeH]F</smiles>

$3 \mathbf{r}, 79 \%$<smiles>O=C(O)c1ccccc1[N+](=O)[O-]</smiles>

3c, $61 \%$<smiles>COc1cc(C(=O)O)ccc1O</smiles>

3d, $65 \%$<smiles>O=C(SCF)c1ccc(-c2ccccc2)cc1</smiles>

3g, $55 \%$<smiles>N#Cc1cccc(C(=O)[SeH]F)c1</smiles>

3k, $73 \%$<smiles>CCCCCCCCCCCC(=O)[SeH2]F</smiles>

3o, $85 \%$<smiles>CCCC(=O)C(C)Cc1ccc(CC(C)C)cc1</smiles>

3s, $85 \%$<smiles>O=C(F)c1ccc(Cl)cc1</smiles>

3h, $68 \%$<smiles>O=C(SCF)c1ccc2ccccc2c1</smiles>

3I, $72 \%$<smiles>O=C(CCc1ccccc1)[SeH]F</smiles>

3p, $88 \%$<smiles>CCCC(=O)C1CCN(C(=O)c2ccccc2)CC1</smiles>

3t, $67 \%$<smiles>CC(C)[C@H]1CC[C@@H](C)C[C@@H]1OC(=O)c1ccc(C(=O)SCF)cc1</smiles>

3u, $46 \%$, from (-)-menthol

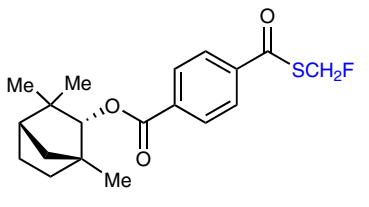

3v, $54 \%$, from (+)-fenchol

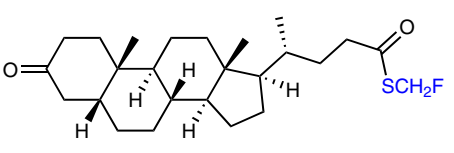

$3 w, 51 \%$, from lithocholic acid difluoromethylthiolation (with $\mathbf{2 b}, \mathrm{PhSO}_{2} \mathrm{SCF}_{2} \mathrm{H}$ )

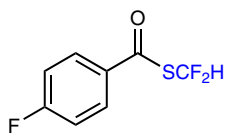

$3 \mathbf{x}, 89 \%$<smiles>COCCOCC(=O)c1ccc2ccccc2c1</smiles>

3y, $65 \%$<smiles>O=C(c1ccc(F)cc1)c1ccc(-c2ccccc2)cc1</smiles>

3z, $50 \%$

Fig. 2 Aldehydes scope for C-H fluoromethylthiolation. [a] Reaction conditions unless otherwise noted: 1 (0.3 mmol), 2 (0.2 mmol), eosin Y (4 mol\%), and tert-butanol $(2.0 \mathrm{~mL})$ in an argon-filled Schlenk tube $(20 \mathrm{~mL})$ at room temperature $\left(\sim 27^{\circ} \mathrm{C}\right)$ under $470 \mathrm{~nm}$ light $(18 \mathrm{~W}$ LED) irradiation.

$\mathrm{SO}_{2}$ group were examined and methanesulfonyl alkyne 13aa was identified as the optimal reagent, probably due to the small steric hinderance (see Supplementary Tables 2 and 3 for optimization study). Diverse substituents (e.g., $\mathrm{F}, \mathrm{Cl}, \mathrm{Br}, \mathrm{CF}_{3}$ ) could be incorporated in arylaldehydes to produce ynones $14 \mathbf{a}-\mathbf{g}$ in moderate yields (41-69\%). Aldehydes possessing heteroaromatics such as thiophene (14h) were suitable substrates as well. Aliphatic aldehydes including both linear (14i, 14j) and branched $(\mathbf{1 4 k}-\mathbf{m})$ alkyl substituents participated in the alkynylation more efficiently to afford ynones in good yields (70-84\%). Moreover, aldehydes derived from lithocholic acid and dihydrocholesterol underwent the transformations smoothly, leading to the facile formation of 14n $(73 \%)$ and 140 (22\%), respectively. Next, the scope regarding alkynyl sulfone $\mathbf{1 3}$ was explored. The protocol was feasible for both arylalkynyl sulfones (14p-u) bearing a variety of functionalities (e.g., $\mathrm{Cl}, \mathrm{CO}_{2} \mathrm{Me}, \mathrm{OMe}$ ) and heteroarylalkynyl sulfones $(\mathbf{1 4 v})$ to produce the corresponding ynones with moderate to good yields $(42-72 \%)$.

Preliminary study on aldehydic $\mathrm{C}-\mathrm{H}$ azidation and alkenylation and scale-up in continuous-flow reactors. To further showcase the versatility of eosin Y-HAT photocatalysis with sulfone reagents, aldehydic $\mathrm{C}-\mathrm{H}$ azidation and alkenylation were investigated (Fig. 7a). Our preliminary study illustrated that triflic azide $\left(\mathrm{CF}_{3} \mathrm{SO}_{2} \mathrm{~N}_{3}\right) 15$ could be applied to forge $\mathrm{C}-\mathrm{N}$ bonds, delivering acyl azides (16a, 16b) in moderate yields (55-58\%). This protocol provides a mild alternative to previous aldehydic $\mathrm{C}-\mathrm{H}$ azidation reactions, which require either excess oxidants ${ }^{57,58}$ 
a Thioester $\mathbf{4}$ observed as a side-product in aldehydic $\mathrm{C}-\mathrm{H}$ fluoromethylthiolation<smiles>COc1ccc(C=O)cc1</smiles>

$1 \mathrm{~b}(0.3 \mathrm{mmol})$
$\mathrm{PhSO}_{2} \mathrm{SCH}_{2} \mathrm{~F}$

2a $(0.2 \mathrm{mmol})$

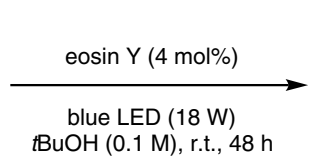

$\mathrm{BuOH}(0.1 \mathrm{M})$, r.t., $48 \mathrm{~h}$<smiles>COc1ccc(C(=O)SCF)cc1</smiles>

3b, $75 \%$

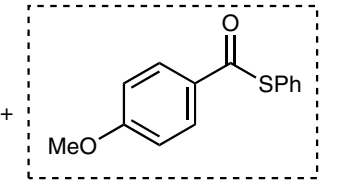

$4 b, 22 \%$

bElucidation of the reason for the formation of side-product 4

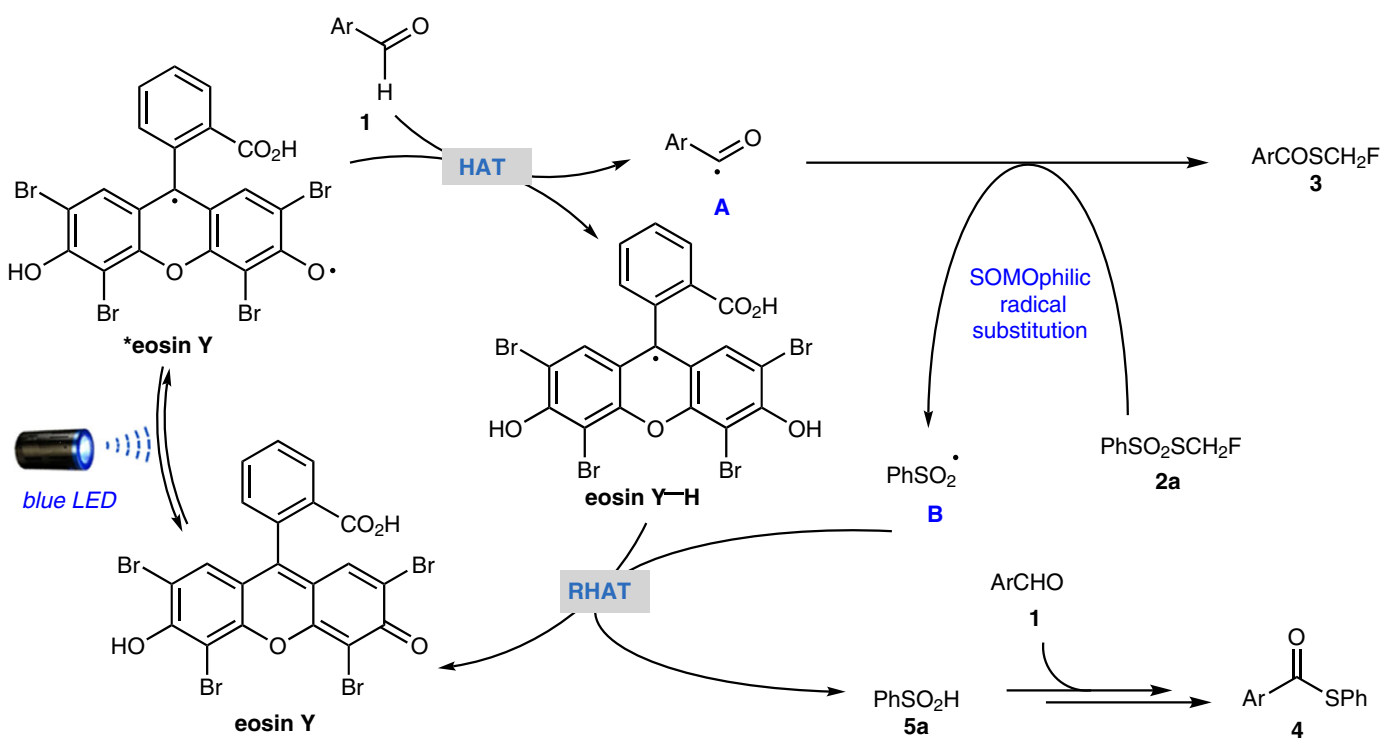

C Discloure of odorless aldehydic $\mathrm{C}-\mathrm{H}$ arylthiolation<smiles>COc1ccc(C=O)cc1</smiles>

1b $(0.4 \mathrm{mmol})$<smiles>O=S(=O)(O)c1ccccc1</smiles>

$5 a(0.2 \mathrm{mmol})$

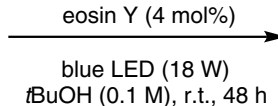

$\mathrm{BuOH}(0.1 \mathrm{M})$, r.t. $48 \mathrm{~h}$

Fig. 3 Discovery of aldehydic C-H thiolation using arylsulfinic acid as an odorless sulfur reagent. a Thioester $\mathbf{4}$ observed as a side-product in aldehydic $\mathrm{C}-\mathrm{H}$ fluoromethylthiolation. $\mathbf{b}$ Possible rationale for the formation of side-product $\mathbf{4}$. c Development of odorless aldehydic $\mathrm{C}-\mathrm{H}$ thiolation.

or inconvenient reagents ${ }^{59}$. Aldehydic $\mathrm{C}-\mathrm{H}$ alkenylation was also feasible using (E)-1,2-bis(phenylsulfonyl)ethene $\mathbf{1 7}$ as the alkenylation reagent, delivering enone 18 in $40 \%$ yield. Finally, the aldehydic $\mathrm{C}-\mathrm{H}$ monofluoromethylation reaction was smoothly transferred to an operationally simple continuous-flow reactor to achieve $>15 \mathrm{~g}$ per day production, indicating the potential of our strategy for large-scale synthesis (Fig. 7b).

\section{Discussion}

In summary, we have demonstrated a versatile platform for aldehydic $\mathrm{C}-\mathrm{H}$ functionalization by merging neutral eosin Y-HAT photocatalysis with a variety of sulfone-based SOMOphiles to directly construct acyl-S, acyl-C and acyl-N bonds. The eosin $\mathrm{Y}$-sulfone system will serve as a more green and sustainable method with easier handling for aldehydic functionalization compared to existing catalytic/stoichiometric systems and has several practically or mechanistically notable features. First, $\mathrm{PhSO}_{2}-\mathrm{SCH}_{x} \mathrm{~F}_{y} 2$ proved particularly effective for metal-, additive- and oxidant-free fluoromethythiolation with diverse aldehydes, including complex natural product derivatives. The fluoromethythiolation reaction was performed under continuous- flow conditions to achieve a productivity of $15 \mathrm{~g}$ per day. Second, arylsulfinic acid $\left(\mathrm{ArSO}_{2} \mathrm{H}\right)$, as an odorless and easily accessible reagent, was employed for arylthiolation of aldehydes. A preliminary mechanistic study supported that an in situ-generated arylthiosulfonate $\left(\mathrm{ArSO}_{2}-\mathrm{SAr}\right)$ species participated in the subsequent radical substitution step. Third, the acyl-C(sp) bond was successfully forged via acyl radical addition-sulfonyl radical elimination with a methanesulfonyl alkyne. Finally, exploiting the versatility of radical addition-elimination, the present strategy was further extended to aldehydic $\mathrm{C}-\mathrm{H}$ azidation and alkenylation. Extension of the $\mathrm{C}-\mathrm{H}$ substrate scope to abundant alkanes and expanding the chemical space of sulfone SOMOphilic reagents to new reaction patterns are currently under investigation in our laboratory.

\section{Methods}

General procedure of neutral-eosin Y-photocatalyzed aldehydic C-H fluoromethylthiolation. A $20 \mathrm{~mL}$ Schlenk tube equipped with a magnetic stir bar was charged with eosin Y $(0.008 \mathrm{mmol}, 5.2 \mathrm{mg})$, aldehyde $1(0.3 \mathrm{mmol})$, and fluoromethylthiolation reagents $2(0.2 \mathrm{mmol})$. Then, $2.0 \mathrm{~mL}$ of anhydrous tertbutanol was added. The Schlenk tube was connected to Schlenk line and freeze-pump-thaw was performed for three times to completely remove air 


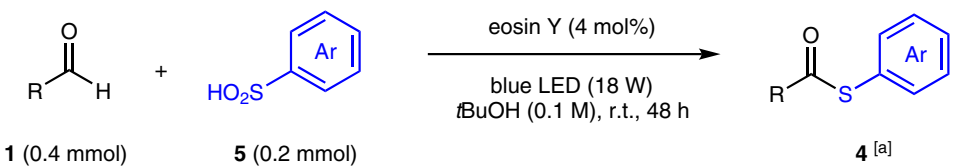<smiles>Cc1ccc(SC(=O)c2ccccc2)cc1</smiles>

4a, $64 \%$<smiles>Cc1ccc(SC(=O)c2ccccc2C)cc1</smiles>

4f, $71 \%$<smiles>COc1ccc(C(=O)Sc2ccc(C)cc2)cc1</smiles>

4c, $63 \%$<smiles>CCNc1ccc(C(=O)Sc2ccc([N+](=O)[O-])cc2)cc1</smiles>

4d, $46 \%$<smiles>CC(=O)Oc1ccc(C(=O)Sc2ccc(C)cc2)cc1</smiles>

4e, $52 \%$<smiles>Cc1ccc(SC(=O)c2cccc(C)c2)cc1</smiles>

$4 g, 64 \%$<smiles>O=C(Sc1ccc([N+](=O)[O-])cc1)c1ccc(F)cc1</smiles>

$4 h, 68 \%$<smiles>Cc1ccc(SC(=O)c2ccc(C(F)(F)F)cc2)cc1</smiles>

$4 i, 65 \%$<smiles>CC(=O)c1cccc(C(=O)Sc2ccc(C)cc2)c1</smiles>

4j, $56 \%$

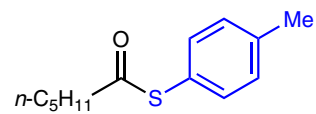

4n, $50 \%$<smiles>Cc1ccccc1C(=O)Sc1ccc(Cl)cc1</smiles>

$4 \mathbf{r}, 48 \%$<smiles>Cc1ccc(SC(=O)c2ccc3c(c2)OC(F)(F)O3)cc1</smiles>

$4 k, 68 \%$<smiles>Cc1ccc(SC(=O)C2CC2)cc1</smiles>

4o, $29 \%$<smiles>Cc1ccccc1C(=O)Sc1ccc(C(F)(F)F)cc1</smiles>

4s, $61 \%$<smiles>Cc1ccc(SC(=O)c2cc3ccccc3s2)cc1</smiles>

4I, $31 \%$<smiles>Cc1ccccc1C(=O)Sc1ccccc1</smiles>

4p, $57 \%$<smiles>Cc1ccccc1C(=O)Sc1ccc2ccccc2c1</smiles>

4t, $59 \%$<smiles>Cc1ccc(SC(=O)c2ccco2)cc1</smiles>

$4 m, 22 \%$<smiles>COc1ccccc1SC(=O)c1ccccc1C</smiles>

4q, $57 \%$<smiles>CC(=O)c1sccc1SC(=O)c1ccccc1C</smiles>

$4 u, 40 \%$

Fig. 4 Scope of the odorless aldehydic C-H thiolation. [a] Reaction conditions unless otherwise noted: 1 (0.4 mmol), $2(0.2 \mathrm{mmol})$, eosin Y (4 mol\%), and tert-butanol $(2.0 \mathrm{~mL})$ in an argon-filled Schlenk tube $(20 \mathrm{~mL})$ at room temperature $\left(\sim 27^{\circ} \mathrm{C}\right)$ under $470 \mathrm{~nm}$ light $(18 \mathrm{~W}$ LED) irradiation.

inside the reaction mixture. Eventually the Schlenk tube was refilled with an atmosphere of argon at room temperature and sealed. The reaction vessel was surrounded by a coil of blue LED strip $(2 \mathrm{~m}, 18 \mathrm{~W})$. Then the reaction was running at ambient temperature $\left(\sim 27^{\circ} \mathrm{C}\right)$ using a fan to cool down the reaction mixture and stopped after $48 \mathrm{~h}$. The solvent was removed under reduced pressure and the crude mixture was purified by silica gel column chromatography or prepared TLC (eluent: hexane/diethyl ether or hexane/ethyl acetate; 10/1-3/1) to give the corresponding product 3 . Note that the workup procedure was performed under weak vacuum $(\sim 50 \mathrm{mbar})$ and low temperature $\left(\sim 30^{\circ} \mathrm{C}\right)$ due to volatility of the corresponding product 3 .

\section{General procedure of neutral-eosin Y-photocatalyzed aldehydic C-H aryl-} thiolation. A $20 \mathrm{~mL}$ Schlenk tube equipped with a magnetic stir bar was charged with eosin $\mathrm{Y}(0.008 \mathrm{mmol}, 5.2 \mathrm{mg})$, aldehyde $\mathbf{1}(0.4 \mathrm{mmol})$, and arylsulfinic acid 5 $(0.2 \mathrm{mmol})$. Then, $2.0 \mathrm{~mL}$ of anhydrous tert-butanol was added. The Schlenk tube was connected to Schlenk line and freeze-pump-thaw was performed for three times to completely remove air inside the reaction mixture. Eventually the Schlenk tube was refilled with an atmosphere of argon at room temperature and sealed. The reaction vessel was surrounded by a coil of blue LED strip $(2 \mathrm{~m}, 18 \mathrm{~W})$. Then the reaction was running at ambient temperature $\left(\sim 27^{\circ} \mathrm{C}\right)$ using a fan to cool down the reaction mixture and stopped after $48 \mathrm{~h}$. The solvent was removed under reduced pressure and the crude mixture was purified by silica gel column chromatography or prepared TLC (eluent: hexane/diethyl ether or hexane/ethyl acetate; $10 / 1-3 / 1)$ to give the corresponding product 4.
General procedure of neutral-eosin Y-photocatalyzed aldehydic C-H alkynylation. A $20 \mathrm{~mL}$ Schlenk tube equipped with a magnetic stir bar was charged with eosin Y $(0.008 \mathrm{mmol}, 5.2 \mathrm{mg})$, aldehyde $\mathbf{1}(0.4 \mathrm{mmol})$, acetylenic sulfone reagents $13(0.2 \mathrm{mmol})$. Then, $2.0 \mathrm{~mL}$ of anhydrous tert-butanol was added. The Schlenk tube was connected to Schlenk line and freeze-pump-thaw was performed for three times to completely remove air inside the reaction mixture. Eventually the Schlenk tube was refilled with an atmosphere of argon at room temperature and sealed. The reaction vessel was surrounded by a coil of blue LED strip $(2 \mathrm{~m}, 18 \mathrm{~W})$ Then the reaction tubes were placed in a water bath covered by top oil layer (to prevent evaporation of water bath). The reaction was running at $60^{\circ} \mathrm{C}$ and stopped after $24 \mathrm{~h}$. The solvent was removed under reduced pressure and the crude mixture was purified by silica gel column chromatography or prepared TLC (eluent: hexane/diethyl ether or hexane/ethyl acetate; 10/1-3/1) to give the corresponding product 14.

Computational details. Density functional theory calculations were performed to shed light on the mechanism of eosin Y regeneration (Supplementary Fig. 17). RHAT (red line) is the favored pathway, which features a barrier $2.1 \mathrm{kcal} / \mathrm{mol}$ lower than an alternative single electron transfer (SET, black line). The geometries optimization in this study was performed at the UB3LYP density functional with a standard def2-SVP basis set. The nature of the stationary points (minima with no imaginary frequency or transition states with one imaginary frequency) were confirmed. The free energies of the optimized geometries were calculated at the same level of theory, considering the solvent effect of acetone using an SMD continuum solvation model. Unless specified otherwise, the Gibbs free energy was used throughout. For 
a

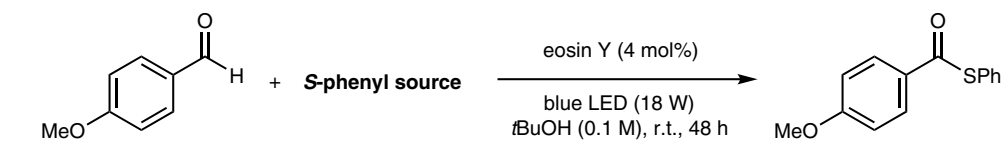

(0.2 mmol)

$4 b$

\begin{tabular}{ccc}
\hline entry & S-phenyl source & isolated yield of $4 \mathbf{b}(\%)$ \\
\hline 1 & $\mathrm{PhSO}_{2} \mathrm{H}(\mathbf{5 a})$ & 68 \\
2 & $\mathrm{PhSO}_{3} \mathrm{H}(\mathbf{6})$ & 10 \\
3 & $\mathrm{PhSH}(\mathbf{7})$ & 0 \\
4 & $\mathrm{PhSSPh}(\mathbf{8})$ & 0 \\
5 & $\mathrm{PhSO}_{2} \mathrm{SPh}(9 \mathbf{a})$ & 67 \\
6 & $\mathrm{PhSO}_{2} \mathrm{O}_{2} \mathrm{SPh}(\mathbf{1 0})$ & 15 \\
\hline
\end{tabular}

b<smiles>O=S(=O)(O)c1ccccc1</smiles>

$5 a(0.2 \mathrm{mmol})$

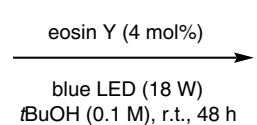
tBuOH $(0.1 \mathrm{M})$, r.t., $48 \mathrm{~h}$<smiles>O=S(=O)(c1ccccc1)c1ccccc1</smiles>

9a, 32\% $(0 \%, w / 0$ eosin $Y)$<smiles>O=S(=O)(O)c1ccccc1</smiles>

6, ESI-MS observed

C

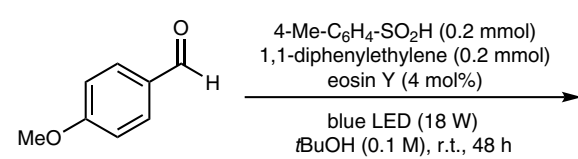

1b $(0.4 \mathrm{mmol})$<smiles>Cc1ccc(S(=O)(=O)C=C(c2ccccc2)c2ccccc2)cc1</smiles>

11, $335.3[\mathrm{M}+\mathrm{H}]^{+}$ ESI-MS detected<smiles>COc1ccc(C(=O)C=C(c2ccccc2)c2ccccc2)cc1</smiles>

$12,315.3[\mathrm{M}+\mathrm{H}]^{+}$

d

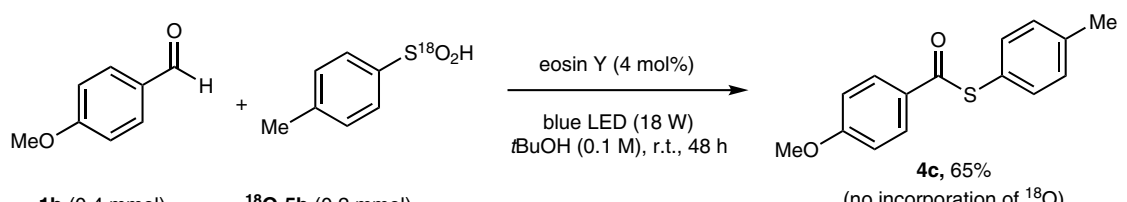

e

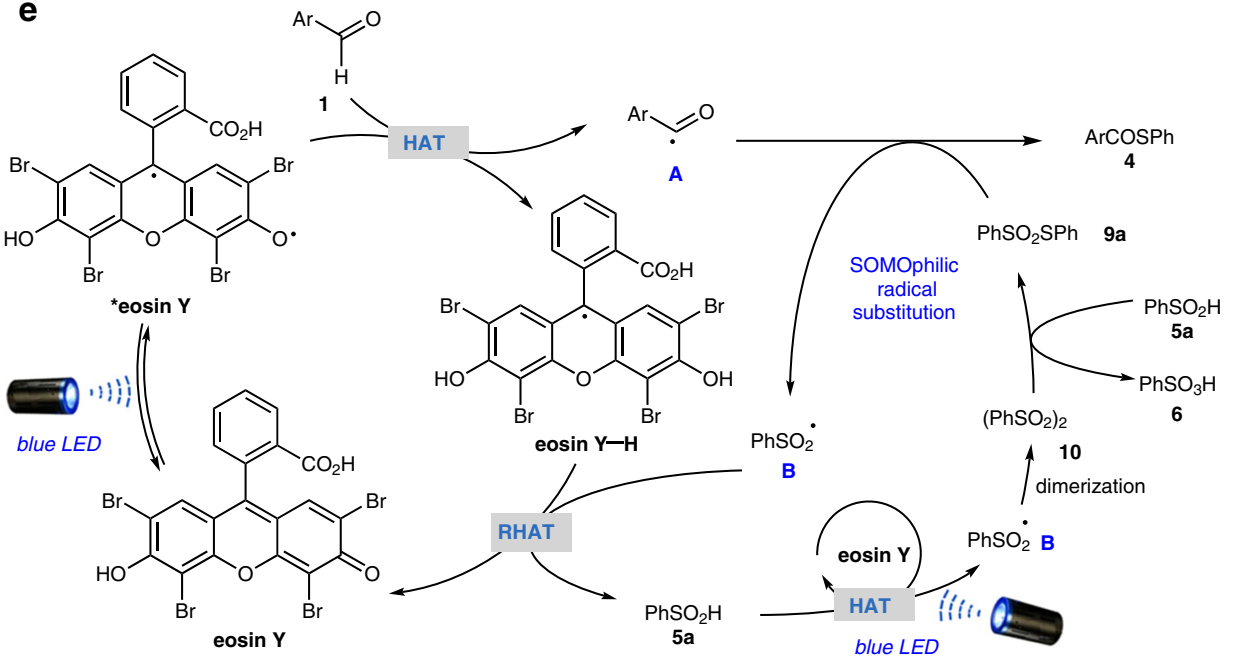

Fig. 5 Proposed mechanism of aldehydic C-H arylthiolation with supporting evidence. a Evaluation of different S-phenyl sources. $\mathbf{b}$ Eosin $Y$ photocatalytic formation of S-phenyl benzenethiosulfonate $\mathbf{9 a}$ from benzenesulfinic acid $\mathbf{5 a}$. c Radical trapping experiments. $\mathbf{d}{ }^{18} \mathrm{O}-L a b e l i n g$ experiments. e Proposed plausible mechanisms.

transition state, intrinsic reaction coordinate calculations were performed to verify whether it connected with correct reactants and products or intermediates. All calculations were performed using the Gaussian 16 Rev. A.03 software suite ${ }^{60}$.

\section{Data availability}

The authors declare that all other data supporting the findings of this study are available within the article and Supplementary Information files, and also are available from the corresponding author upon request. Source data are provided with this paper. 

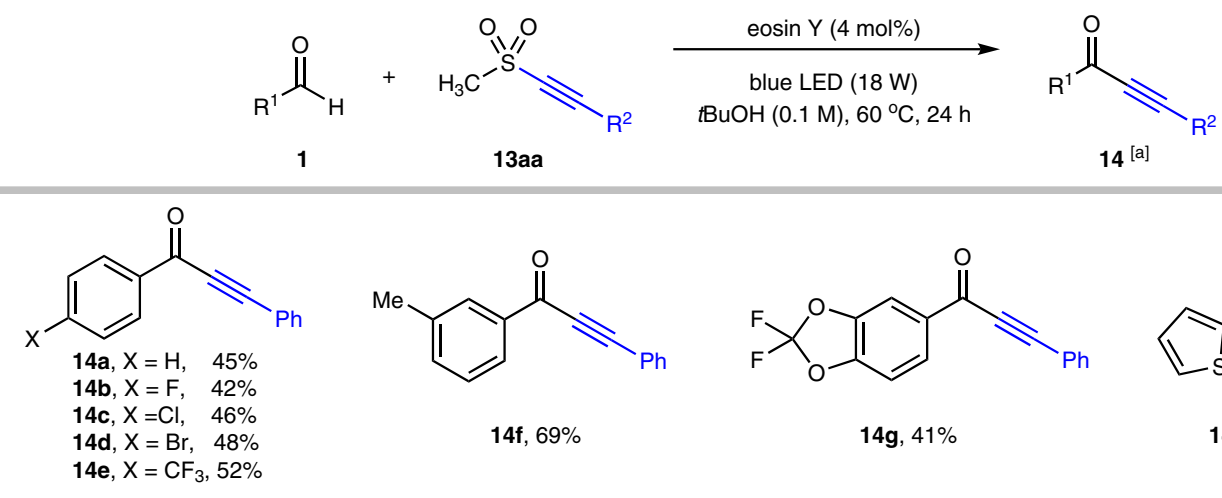<smiles>Cc1cccc(C(=O)C#Cc2ccccc2)c1</smiles>

$14 f, 69 \%$<smiles>O=C(C#Cc1ccccc1)c1ccc2c(c1)OC(F)(F)O2</smiles>

14g, $41 \%$<smiles>O=C(C#CC#Cc1ccccc1)c1ccccc1</smiles>

$14 h, 42 \%$<smiles>O=C(C#CC=Pc1ccccc1)c1ccccc1</smiles>

$14 i, 74 \%$

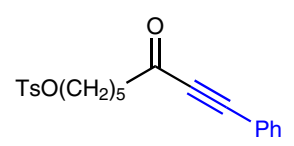

14j, $70 \%$<smiles>CCCCCCCC(=O)C#CPc1ccccc1</smiles>

$14 k, 71 \%$<smiles>O=C(C#CPc1ccccc1)C1CCCCC1</smiles>

$14 I, 84 \%$

$14 \mathrm{~m}, 80 \%$<smiles>C[C@H](CCC(=O)C#CPc1ccccc1)C1CCC2C3CC[C@@H]4CC(=O)CCC4(C)C3CCC21C</smiles>

14n, $73 \%$, from lithocholic acid

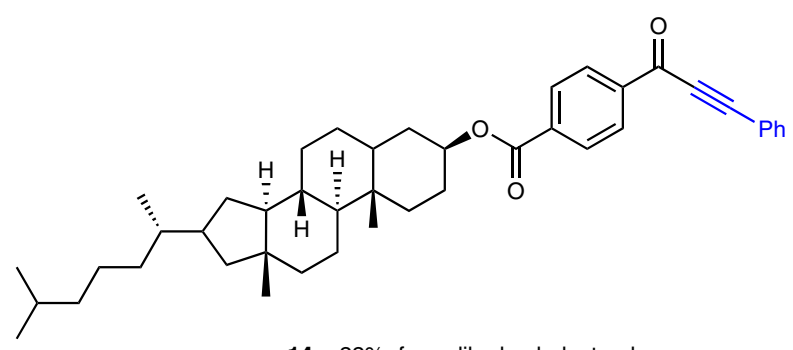

$140,22 \%$, from dihydrocholesterol

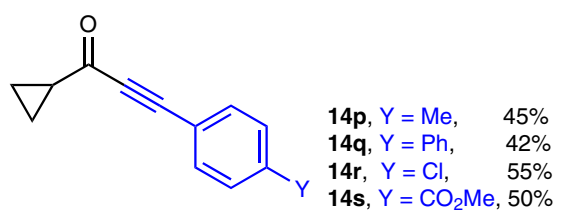<smiles>Cc1ccccc1C#CC(=O)C1CC1</smiles>

$14 t, 72 \%$<smiles>COc1ccccc1C#CC(=O)C1CC1</smiles>

$14 u, 52 \%$<smiles>O=C(C#Cc1ccsc1)C1CC1</smiles>

$14 v, 51 \%$

Fig. 6 Substrate scope of aldehydic C-H alkynylation. [a] Reaction conditions: $\mathbf{1}(0.4 \mathrm{mmol}), \mathbf{1 3}(0.2 \mathrm{mmol})$, eosin Y (4 mol\%), and tert-butanol (2.0 mL) in an argon-filled Schlenk tube $(20 \mathrm{~mL})$ at $60^{\circ} \mathrm{C}$ under $470 \mathrm{~nm}$ light (18 W LED) irradiation.

a
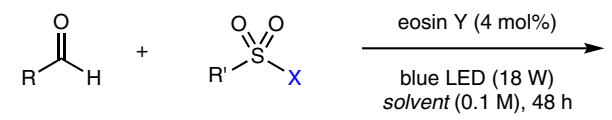

${ }_{R}^{O}$

$1(0.4 \mathrm{mmol})$

$(0.2 \mathrm{mmol})$<smiles>NC(=O)c1ccc(-c2ccccc2)cc1</smiles>

$16 a, 58 \%$<smiles>COc1ccc(C(N)=O)cc1</smiles>

$16 b, 55 \%$ alkenylation (with $\left.(E)-\mathrm{PhSO}_{2} \mathrm{CH}=\mathrm{CHSO}_{2} \mathrm{Ph} 17\right)^{[\mathrm{b}]}$<smiles>COc1ccc(C(=O)/C=C/S(=O)(=O)c2ccccc2)cc1</smiles>

$18,40 \%$

b<smiles>COc1ccc(C=O)cc1</smiles>
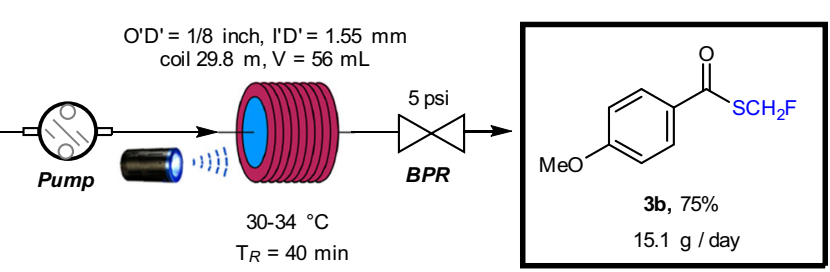

Fig. 7 Aldehydic C-H diversification and scale-up synthesis in flow. a Aldehydic $\mathrm{C}-\mathrm{H}$ azidation and vinylation. Reaction conditions unless otherwise noted: $1(0.4 \mathrm{mmol})$, sulfone $(0.2 \mathrm{mmol})$, eosin $\mathrm{Y}(4 \mathrm{~mol} \%)$, and solvent $(2.0 \mathrm{~mL})$ in an argon-filled Schlenk tube (20 mL) under $470 \mathrm{~nm}$ light $(18 \mathrm{~W}$ LED) irradiation. [a] Reaction was performed in $\mathrm{CH}_{3} \mathrm{CN}$ at room temperature. [b] Reaction was performed in ethyl acetate at $80^{\circ} \mathrm{C}$. $\mathbf{b}$ Reaction scale-up in continuous-flow microtubing reactors. Psi pound per square inch. 
Received: 21 July 2021; Accepted: 18 November 2021;

Published online: 10 December 2021

\section{References}

1. Giese, B. Formation of CC bonds by addition of free radicals to alkenes. Angew. Chem. Int. Ed. Engl. 22, 753-764 (1983).

2. Boger, D. L. \& Mathvink, R. J. Acyl radicals: intermolecular and intramolecular alkene addition reactions. J. Org. Chem. 57, 1429-1443 (1992).

3. Proctor, R. S. J. \& Phipps, R. J. Recent advances in Minisci-type reactions. Angew. Chem. Int. Ed. 58, 13666-13699 (2019).

4. Zhang, X. \& MacMillan, D. W. C. Direct aldehyde C-H arylation and alkylation via the combination of nickel, hydrogen atom transfer, and photoredox catalysis. J. Am. Chem. Soc. 139, 11353-11356 (2017).

5. Chu, L., Lipshultz, J. M. \& Macmillan, D. W. C. Merging photoredox and nickel catalysis: the direct synthesis of ketones by the decarboxylative arylation of a-oxo acids. Angew. Chem. Int. Ed. 54, 7929-7933 (2015).

6. Wang, L. et al. Direct C-H arylation of aldehydes by merging photocatalyzed hydrogen atom transfer with palladium catalysis. ACS Catal. 10, 7543-7551 (2020).

7. Chatgilialoglu, C., Crich, D., Komatsu, M. \& Ryu, I. Chemistry of acyl radicals. Chem. Rev. 99, 1991-2070 (1999).

8. Raviola, C., Protti, S., Ravelli, D. \& Fagnoni, M. Photogenerated acyl/ alkoxycarbonyl/carbamoyl radicals for sustainable synthesis. Green. Chem. 21, 748-764 (2019).

9. Banerjee, A., Lei, Z. \& Ngai, M.-Y. Acyl radical chemistry via visible-light photoredox catalysis. Synthesis 51, 303-333 (2019).

10. Penteado, F. et al. a-Keto acids: acylating agents in organic synthesis. Chem. Rev. 119, 7113-7278 (2019).

11. Liu, J. et al. Visible-light-mediated decarboxylation/oxidative amidation of $\alpha$ keto acids with amines under mild reaction conditions using $\mathrm{O}_{2}$. Angew. Chem. Int. Ed. 53, 502-506 (2014).

12. De Pedro Beato, E., Mazzarella, D., Balletti, M. \& Melchiorre, P. Photochemical generation of acyl and carbamoyl radicals using a nucleophilic organic catalyst: applications and mechanism thereof. Chem. Sci. 11, 6312-6324 (2020).

13. Capaldo, L., Riccardi, R., Ravelli, D. \& Fagnoni, M. Acyl radicals from acylsilanes: photoredox-catalyzed synthesis of unsymmetrical ketones. ACS Catal. 8, 304-309 (2018)

14. Kumar, P. et al. Aldehydes: magnificent acyl equivalents for direct acylation. Org. Biomol. Chem. 18, 7987-8033 (2020).

15. Liu, Y.-L., Ouyang, Y.-J., Zheng, H., Liu, H. \& Wei, W.-T. Recent advances in acyl radical enabled reactions between aldehydes and alkenes. Chem. Commun. 57, 6111-6120 (2021).

16. Wang, J., Liu, C., Yuan, J. \& Lei, A. Copper-catalyzed oxidative coupling of alkenes with aldehydes: direct access to $\alpha, \beta$-unsaturated ketones. Angew. Chem. Int. Ed. 52, 2256-2259 (2013).

17. $\mathrm{Xu}, \mathrm{B}$. et al. Radical fluoroalkylthiolation of aldehydes with $\mathrm{PhSO}_{2} \mathrm{SR}_{\mathrm{f}}\left(\mathrm{R}_{\mathrm{f}}=\right.$ $\mathrm{CF}_{3}, \mathrm{C}_{2} \mathrm{~F}_{5}, \mathrm{CF}_{2} \mathrm{H}$ or $\mathrm{CH}_{2} \mathrm{~F}$ ): a general protocol for the preparation of fluoroalkylthioesters. Org. Chem. Front. 5, 2163-2166 (2018).

18. Guo, S.-H. et al. Synthesis of difluoromethylthioesters from aldehydes. Angew. Chem. Int. Ed. 57, 1663-1667 (2018).

19. Zhang, Y. et al. Organocatalytic transformation of aldehydes to thioesters with visible light. Chem. Eur. J. 25, 8225-8228 (2019).

20. Zhang, Y., Ji, P., Dong, Y., Wei, Y. \& Wang, W. Deuteration of formyl groups via a catalytic radical H/D exchange approach. ACS Catal. 10, 2226-2230 (2020).

21. Dong, J. et al. Light-mediated difluoromethylthiolation of aldehydes with a hydrogen atom transfer photocatalyst. Org. Lett. 22, 8272-8277 (2020).

22. Mukherjee, S., Patra, T. \& Glorius, F. Cooperative catalysis: a strategy to synthesize trifluoromethyl-thioesters from aldehydes. ACS Catal. 8, 5842-5846 (2018).

23. Capaldo, L. \& Ravelli, D. Decatungstate as direct hydrogen atom transfer photocatalyst for SOMOphilic alkynylation. Org. Lett. 23, 2243-2247 (2021).

24. Mukherjee, S., Garza-Sanchez, R. A., Tlahuext-Aca, A. \& Glorius, F. Alkynylation of $\mathrm{C}_{\mathrm{sp} 2}(\mathrm{O})-\mathrm{H}$ bonds enabled by photoredox-mediated hydrogen-atom transfer. Angew. Chem. Int. Ed. 56, 14723-14726 (2017).

25. Capaldo, L., Ravelli, D. \& Fagnoni, M. Direct photocatalyzed hydrogen atom transfer (HAT) for aliphatic C-H bonds elaboration. Chem. Rev. 121, https:// doi.org/10.1021/acs.chemrev.1c00263 (2021).

26. Cao, H., Tang, X., Tang, H., Yuan, Y. \& Wu, J. Photoinduced intermolecular hydrogen atom transfer reactions in organic synthesis. Chem. Catal. 1, 523-598 (2021).

27. Shen, Y., Gu, Y. \& Martin, R. $s p^{3} \mathrm{C}-\mathrm{H}$ arylation and alkylation enabled by the synergy of triplet excited ketones and nickel catalysts. J. Am. Chem. Soc. 140, 12200-12209 (2018).
28. Kamijo, S., Kamijo, K., Maruoka, K. \& Murafuji, T. Aryl ketone catalyzed radical allylation of $\mathrm{C}\left(\mathrm{sp}^{3}\right)-\mathrm{H}$ bonds under photoirradiation. Org. Lett. 18, 6516-6519 (2016)

29. Li, Y., Lei, M. \& Gong, L. Photocatalytic regio- and stereoselective $\mathrm{C}\left(\mathrm{sp}^{3}\right)-\mathrm{H}$ functionalization of benzylic and allylic hydrocarbons as well as unactivated alkanes. Nat. Catal. 2, 1016-1026 (2019).

30. Cao, S., Hong, W., Ye, Z. \& Gong, L. Photocatalytic three-component asymmetric sulfonylation via direct $\mathrm{C}\left(\mathrm{sp}^{3}\right)-\mathrm{H}$ functionalization. Nat. Commun. 12, 2377 (2021)

31. Shen, Y., Dai, Z.-Y., Zhang, C. \& Wang, P.-S. Palladium-catalyzed allylic alkylation via photocatalytic nucleophile generation. ACS Catal. 11, 6757-6762 (2021)

32. Hari, D. P. \& König, B. Synthetic applications of eosin $\mathrm{Y}$ in photoredox catalysis. Chem. Commun. 50, 6688-6699 (2014).

33. Srivastava, V. \& Singh, P. P. Eosin Y catalysed photoredox synthesis: a review RSC Adv. 7, 31377-31392 (2017).

34. Yan, D.-M., Chen, J.-R. \& Xiao, W.-J. New roles for photoexcited eosin Y in photochemical reactions. Angew. Chem. Int. Ed. 58, 378-380 (2019).

35. Fan, X.-Z. et al. Eosin $\mathrm{Y}$ as a direct hydrogen-atom transfer photocatalyst for the functionalization of $\mathrm{C}-\mathrm{H}$ bonds. Angew. Chem. Int. Ed. 57, 8514-8518 (2018).

36. Kuang, Y. et al. Asymmetric synthesis of 1,4-dicarbonyl compounds from aldehydes by hydrogen atom transfer photocatalysis and chiral Lewis acid catalysis. Angew. Chem. Int. Ed. 58, 16859-16863 (2019).

37. Yan, J. et al. A radical smiles rearrangement promoted by neutral eosin $\mathrm{Y}$ as a direct hydrogen atom transfer photocatalyst. J. Am. Chem. Soc. 142, 11357-11362 (2020)

38. Inoa, J., Dominici, G., Eldabagh, R., Foley, J. J. IV \& Xing, Y. Synthetic applications and computational perspectives on eosin $\mathrm{Y}$ induced direct HAT process. Synthesis 53, 2183-2197 (2021).

39. Xia, Y., Wang, L. \& Studer, A. Site-selective remote radical C-H functionalization of unactivated $\mathrm{C}-\mathrm{H}$ bonds in amides using sulfone reagents. Angew. Chem. Int. Ed. 57, 12940-12944 (2018)

40. Wang, L., Xia, Y., Bergander, K. \& Studer, A. Remote site-specific radical alkynylation of unactivated C-H bonds. Org. Lett. 20, 5817-5820 (2018).

41. Roberts, B. P. Polarity-reversal catalysis of hydrogen-atom abstraction reactions: concepts and applications in organic chemistry. Chem. Soc. Rev. 28, 25-35 (1999).

42. Panferova, L. I., Zubkov, M. O., Kokorekin, V. A., Levin, V. V. \& Dilman, A. D. Using the thiyl radical for aliphatic hydrogen-atom transfer: thiolation of unactivated C-H bonds. Angew. Chem. Int. Ed. 60, 2849-2854 (2021).

43. Constantin, T. et al. Aminoalkyl radicals as halogen-atom transfer agents for activation of alkyl and aryl halides. Science 367, 1021-1026 (2020).

44. Zhao, Q., Lu, L. \& Shen, Q. Direct monofluoromethylthiolation with S(fluoromethyl) benzenesulfonothioate. Angew. Chem. Int. Ed. 56, 11575-11578 (2017).

45. Liu, F., Jiang, L., Qiu, H. \& Yi, W. Bunte salt $\mathrm{CH}_{2} \mathrm{FSSO}_{3} \mathrm{Na}$ : an efficient and odorless reagent for monofluoromethylthiolation. Org. Lett. 20, 6270-6273 (2018).

46. Guo, S.-H. et al. Synthesis of monofluoromethylthioesters from aldehydes. Adv. Synth. Catal. 360, 1861-1869 (2018).

47. Deng, H.-P., Zhou, Q. \& Wu, J. Microtubing-reactor-assisted aliphatic C-H functionalization with $\mathrm{HCl}$ as a hydrogen-atom-transfer catalyst precursor in conjunction with an organic photoredox catalyst. Angew. Chem. Int. Ed. 57, 12661-12665 (2018)

48. Morack, T., Mück-Lichtenfeld, C. \& Gilmour, R. Bioinspired radical Stetter reaction: radical umpolung enabled by ion-pair photocatalysis. Angew. Chem., Int. Ed. 58, 1208-1212 (2019)

49. Capaldo, L., Quadri, L. L. \& Ravelli, D. Photocatalytic hydrogen atom transfer: the philosopher's stone for late-stage functionalization? Green. Chem. 22, 3376-3396 (2020).

50. Capaldo, L. \& Ravelli, D. Hydrogen atom transfer (HAT): a versatile strategy for substrate activation in photocatalyzed organic synthesis. Eur. J. Org. Chem. 2017, 2056-2071 (2017).

51. Chen, J.-R., Yan, D.-M., Wei, Q. \& Xiao, W.-J. Photocascade catalysis: a new strategy for cascade reactions. ChemPhotoChem 1, 148-158 (2017).

52. Luo, J. et al. Formation of thioesters by dehydrogenative coupling of thiols and alcohols with $\mathrm{H}_{2}$ evolution. Nat. Catal. 3, 887-892 (2020).

53. Reilly, S. W., Bennett, F., Fier, P. S., Ren, S. M. \& Strotman, N. A. Late-stage ${ }^{18} \mathrm{O}$ labeling of primary sulfonamides via a degradation-reconstruction pathway. Chem. Eur. J. 26, 4251-4255 (2020).

54. Griesser, M., Chauvin, J. P. R. \& Pratt, D. A. The hydrogen atom transfer reactivity of sulfinic acids. Chem. Sci. 9, 7218-7229 (2018).

55. Kice, J. L. \& Bowers, W. K. The mechanism of the disproportionation of sulfinic acids. J. Am. Chem. Soc. 84, 605-610 (1962).

56. Cao, L. et al. Disproportionate coupling reaction of sodium sulfinates mediated by $\mathrm{BF}_{3} \cdot \mathrm{OEt}_{2}$ : an approach to symmetrical/unsymmetrical thiosulfonates. Org. Lett. 20, 4754-4758 (2018). 
57. De Sarkar, S. \& Studer, A. Oxidative amidation and azidation of aldehydes by NHC catalysis. Org. Lett. 12, 1992-1995 (2010).

58. Yadav, V. K., Srivastava, V. P. \& Yadav, L. D. S. Visible light induced azidation of aldehydic $\mathrm{C}-\mathrm{H}$ with carbon tetrabromide and sodium azide. Tetrahedron Lett. 57, 2502-2505 (2016).

59. Shinomoto, Y. et al. Tetra- $n$-butylammonium iodide catalyzed $\mathrm{C}-\mathrm{H}$ azidation of aldehydes with thermally stable azidobenziodoxolone. Org. Lett. 17, 5212-5215 (2015).

60. Frisch, M. J. et al. Gaussian 16, revision C.01 (Gaussian, 2016).

\section{Acknowledgements}

We are grateful for the financial support provided by Pfizer, the National University of Singapore (R-143-000-B60-114), National University of Singapore Flagship Green Energy Program (R-279-000-553-646 and R-279-000-553-731), the National Natural Science Foundation of China (Grant No. 22071170), and the National University of Singapore (Suzhou) Research Institute. We thank Prof. Qilong Shen (SIOC) for the gifted samples of $\mathbf{2 a}$ and $\mathbf{2 b}$. The authors would like to thank Dr. Juan Colberg, Dr. Patrick O'Neill, Dr. Srinivas Reddy Dubbaka, and Dr. Zhihui Peng (Pfizer) for helpful discussion.

\section{Author contributions}

J.Y. discovered and developed the reaction. J.Y., J.L.P., S.D., and J.W. conceived and designed the investigations. X.S. conducted DFT calculations. J.Y., H.T., E.J.R.K., and C.L. performed the experiments. J.Y., H.T., M.Z., and J.W. wrote the manuscript.

\section{Competing interests}

The authors declare no competing interests.

\section{Additional information}

Supplementary information The online version contains supplementary material available at https://doi.org/10.1038/s41467-021-27550-8.

Correspondence and requests for materials should be addressed to Muliang Zhang, Shengquan Duan or Jie Wu.

Peer review information Nature Communications thanks Takashi Koike and the anonymous reviewer(s) for their contribution to the peer review of this work.

Reprints and permission information is available at http://www.nature.com/reprints

Publisher's note Springer Nature remains neutral with regard to jurisdictional claims in published maps and institutional affiliations.

(c) (i) Open Access This article is licensed under a Creative Commons Attribution 4.0 International License, which permits use, sharing, adaptation, distribution and reproduction in any medium or format, as long as you give appropriate credit to the original author(s) and the source, provide a link to the Creative Commons license, and indicate if changes were made. The images or other third party material in this article are included in the article's Creative Commons license, unless indicated otherwise in a credit line to the material. If material is not included in the article's Creative Commons license and your intended use is not permitted by statutory regulation or exceeds the permitted use, you will need to obtain permission directly from the copyright holder. To view a copy of this license, visit http://creativecommons.org/ licenses/by/4.0/.

(C) The Author(s) 2021 